\title{
O PRINCÍPIO EDUCATIVO DO TRABALHO E A IMPORTÂNCIA SOCIAL DA INCLUSÃO DE TRABALHADORES COM DEFICIÊNCIA
}

\author{
Naim Rodrigues de Araújo*
}

\begin{abstract}
RESUMO: Tem-se por objetivo ultrapassar uma compreensão do trabalho como sendo apenas uma troca mercantil e compreendê-lo como uma atividade social central à significação/ressignificação humana. Faz-se um ensaio teórico que propõe uma reflexão a partir dos conceitos de signos e instrumentos apresentados por Vygotsky em debate com o conceito de trabalho real discutido na Ergologia. A aproximação entre a Ergologia e o entendimento de Vygotsky acerca da formação social da mente permite inferir que, assim como os signos são mediadores no desenvolvimento das crianças, na vida adulta, a partir do uso de instrumentos e do contato social, o trabalho se apresenta como uma categoria central que possibilita aos humanos se desenvolverem, serem reconhecidos e se reconhecerem enquanto sujeitos. Logo, o trabalho deve ser concebido com um direito social, não como privilégio de alguns. Portanto, as pessoas com deficiência não podem ter o direito ao trabalho cerceado.
\end{abstract}

PALAVRAS-CHAVE: desenvolvimento humano. Signos. Instrumentos. Trabalho. Inclusão.

\section{THE EDUCATIONAL PRINCIPLE OF WORK AND THE SOCIAL IMPORTANCE OF INCLUDING WORKERS WITH DISABILITIES}

\begin{abstract}
This article aims to go beyond an understanding of work as just a commercial exchange and understand it as a social activity central to human signification/resignification. It is a theoretical essay that proposes a reflection based on the concepts of signs and instruments presented by Vygotsky in debate with the concept of real work discussed in Ergology. The approximation between Ergology and Vygotsky's understanding of the social formation of the mind allows us to infer that, just as signs are mediators in the development of children, in adult life, through the use of instruments and social contact, work becomes presents as a central category that enables humans to develop, being recognized and recognize themselves as subjects. Thus, work must be conceived as a social right, not as a privilege of some. Therefore, people with disabilities cannot have their right to work restrained.
\end{abstract}

KEYWORDS: human development. Signs. Instruments. Work. Inclusion.

\footnotetext{
* Mestre em Educação e Docência pela Universidade Federal de Minas Gerais. Técnico administrativo em educação na Universidade Federal de Minas Gerais. Atua em pesquisas relacionadas à inclusão, trabalho e educação. E-mail: naim@ufmg.br Orcid: https://orcid.org/0000-0003-4966-816X
} 


\section{Introdução}

Este artigo propõe um debate acerca da centralidade do trabalho, buscando, sobretudo, ultrapassar uma compreensão limitada do trabalho enquanto uma troca mercantil de força de trabalho por dinheiro e entendê-lo como uma atividade mediadora entre a natureza e os humanos. Assim, buscase ampliar o debate a partir de um diálogo entre as internalizações mediadas que ocorrem na infância com as internalizações mediadas que ocorrem no trabalho na vida adulta. Entender o trabalho como uma atividade de aprendizagem, ensinamento e internalização é entendê-lo como uma atividade humanizadora, e que, portanto, não pode ser privilégio de alguns em detrimento de outros.

Destaca-se, assim como Minayo (2002, p.14), que metodologia é “[...] o caminho do pensamento e a prática exercida na abordagem da realidade". Nesse sentido, propõe-se aqui o caminho da aproximação teórica entre as proposições de Vygotsky $^{1}$ acerca do desenvolvimento humano tratado na obra: "A formação social da mente: o desenvolvimento dos processos psicológicos superiores" e o arcabouço teórico fornecido pela Ergologia ${ }^{2}$ acerca do trabalho, sobretudo a partir do conceito de trabalho real ${ }^{3}$ apresentado por Ives Schwartz ${ }^{4}$.

Trata-se de um ensaio teórico, busca-se mais do que respostas, mas, principalmente, novas perguntas que possam ampliar a discussão. Para Meneghetti (2011) o ensaio não se limita à história, ele cria uma nova história. Ao propor uma reflexão aproximativa entre o desenvolvimento social mediado na infância com a centralidade social do trabalho na vida adulta quer-se vislumbrar uma nova história, uma construção que não desconsidere a singularidade humana, que está, sempre, em busca de constante significação/ressignificação no trabalho.

O ensaio permite que os sujeitos relacionados a ele desenvolvam sua autonomia intelectual e formem seu próprio conhecimento, sem cair na racionalidade totalitária, que tende a enquadrar a compreensão da realidade a partir do estabelecimento de verdades aparentes. Por este motivo, o ensaio não necessita apresentar conclusões afirmativas. Os questionamentos, em forma de reflexões e de novas perguntas, são mais relevantes do que conclusões que estabelecem o marco final e definitivo (MENEGHETTI, 2011, p. 330).

Interessa-nos, portanto, refletir sobre o trabalho, mais especificamente sobre sua função mediadora e humanizadora. Longe de visar conclusões, a discussão propõe uma reflexão constante. E, ao falar-se da complexidade do trabalho, a abordagem ergológica ajuda, sobretudo por entender que o

\footnotetext{
${ }^{1}$ Para além das discussões/ contribuições em diversos campos do pensamento como a psicologia e a filosofia, foi pioneiro no conceito de que o desenvolvimento intelectual das crianças ocorre em função das interações sociais e condições de vida.

${ }^{2}$ É uma abordagem pluridisciplinar do trabalho; busca compreender as diferenças entre o trabalho real e o trabalho prescrito.

${ }^{3}$ Para a ergologia "O trabalho real, na verdade, é o resultado das renormatizações, não dá estrita aplicação e execução das normas. Ou melhor, é a ‘execução’ das normas através das renormatizações (SCHWARTZ, 2006, p. 462).

${ }^{4}$ Filósofo especialista em análise da atividade de trabalho. É reconhecido como fundador da abordagem ergológica, uma corrente da análise pluridisciplinar de situações do trabalho.
} 
trabalho real, ou seja, aquele que de fato é realizado pelo trabalhador, é sempre diferente do que era previsto, pois, cada trabalhador executa as tarefas de acordo com sua singularidade, suas experiências, sentimentos, desejos, angústias, intepretações; enfim, é sempre uma transformação interna e externa ao mesmo tempo.

A abordagem ergológica do trabalho permite uma aproximação com as proposições de Vygotsky acerca do desenvolvimento humano, sobretudo ao discutirmos a função mediadora de signos ${ }^{5}$ e instrumentos ${ }^{6}$. Em uma reflexão aproximativa entre os conceitos de trabalho real, signos e instrumentos, coloca-se em discussão a importância social do trabalho, em especial às pessoas com deficiência, que nem sempre tiveram a oportunidade de mediação adequada em etapas anteriores da vida para potencializarem seu desenvolvimento. Nesse contexto o trabalho se torna uma oportunidade de ressignificação humana, transformação e aprendizado. Deve ser compreendido, portanto, como um direito social.

Este texto está estruturado em três seções. Incialmente é abordado o trabalho das pessoas com deficiência do ponto de vista legal, principalmente em relação à legislação vigente, seus limites, avanços e perspectivas de retrocessos no contexto atual. Em seguida, discute-se a formação social da mente a partir dos escritos de Vygotsky. Finalmente, na última seção, faz-se uma abordagem aproximativa entre a Ergologia, o desenvolvimento social da mente na infância e a função mediadora dos instrumentos de trabalho e das relações sociais que se formam nesse ambiente.

\section{O Direito ao Trabalho à Pessoa com Deficiência}

A inclusão no mercado de trabalho diz respeito, também, à garantia de condições adequadas de sobrevivência às pessoas com deficiência, contudo, o retorno financeiro esperado em uma relação assalariada de trabalho não é o cerne do debate proposto. Neste artigo se compreende, assim como Diniz e Barbosa (2010), que a discussão sobre a reserva de vagas no mercado de trabalho para pessoas com deficiência deve ultrapassar uma abordagem das cotas como uma necessidade de sobrevivência, deve ser vista como uma regulamentação necessária para garantir um direito humanitário às pessoas com deficiência.

As cotas no mercado de trabalho para pessoas com deficiência podem ser entendidas pelo menos de duas maneiras. A primeira, como uma medida política de reconhecimento: não se espera que espontaneamente o mercado reconheça o mérito e a qualificação das pessoas com deficiência para o trabalho, em particular nas situações em que a inclusão do deficiente exige adequações no ambiente ou nas relações de trabalho (FRASER,1998). A segunda, como uma medida política afirmativa de reparação de desigualdades: o trabalho é uma forma efetiva de promoção da mobilidade social das pessoas com deficiência, retirando-as da reclusão doméstica ou da

\footnotetext{
5 É um elemento mediador. Os signos são quaisquer objetos, formas ou fenômenos, exclusivamente humanos, que representam algo diferente de si mesmo. Com exemplos temos os desenhos, as placas, a linguagem escrita e falada e também os símbolos.

${ }^{6}$ Assim como os signos, são instrumentos mediadores. São as ferramentas usadas pelo ser humano para interagir com o mundo. Como exemplos temos copos, cadeiras, machados, facas, garrafas. Animais também podem usar instrumentos, como, por exemplo, o uso de gravetos por chimpanzés.
} 
institucionalização permanente (BARNES; BARTON; OLIVER, 2002). O pressuposto de justiça por trás da política de cotas é de que o trabalho consiste numa esfera fundamental da sociabilidade, traduzindo-se em um direito humano a ser garantido para todas as pessoas (DINIZ; BARBOSA, 2010, p. 208).

A Constituição Federativa de 1988 (CF/1988) trouxe alguns destaques importantes no que diz respeito a inserção de pessoas com deficiência no mercado de trabalho. Nos artigos $3^{\circ}$ e $7^{\circ}$ a CF/1988 destaca que não deve existir nenhum tipo de preconceito, seja de raça, cor, sexo, ou qualquer outra forma de discriminação, além disso, proíbe distinção de salários entre pessoas ditas normais e pessoas com deficiência que exerçam a mesma função; ademais, o $37^{\circ}$ artigo dispõe sobre reserva de vagas em cargos públicos às pessoas com deficiência (BRASIL, 1988). A lei de diretrizes e bases da educação nacional de 1996 (LDB/1996), no capítulo V, trata especificamente da educação especial, destaca em seu 59ªrtigo que é dever das instituições de ensino assegurar educação especial para o trabalho e garantir a integração na vida em sociedade (BRASIL, 1996). Essas regulamentações são importantes, pois, reforçam “[...] a necessidade de adotarmos procedimentos que deem condições reais às pessoas com deficiência ingressarem e permanecerem no mercado de trabalho" (ARAÚJO, 2020, p. 48).

A LBD/1996 representa importante marco histórico, pois estabelece que as escolas devem garantir condições adequadas às necessidades das pessoas com deficiência, contudo, antes da LBD/1996 ser publicada já existia regulamentação de reserva de vagas, tanto no setor público - lei nº. 8112/1990 quanto no setor privado - lei nº $8213 / 1991$ - que só foi regulamentada no ano de 1998 com a resolução $n^{\circ}$. 630/1998. “A empresa que possui acima de 100 empregados deve preencher seus postos de trabalho com 2\% a 5\% de empregados beneficiários da Previdência Social que sejam reabilitados ou com pessoas portadoras de deficiência habilitadas" (BRASIL, 1991).

No ano de 2015 foi promulgada a lei no. 13.146/2015, também conhecida como estatuto da pessoa com deficiência. A lei, que é resultado de um processo histórico de reivindicações e lutas, tornase importante, sobretudo por dispor desde a área social até à inclusão laboral. No terceiro parágrafo do seu $34^{\circ}$ artigo destaca que é vedado qualquer restrição ao trabalho da pessoa com deficiência (Brasil, 2015). Todas essas regulamentações demonstram que houve avanço em termos de garantia de direitos às pessoas com deficiência, conquanto, é preciso conhecer em que medida esses direitos estão sendo efetivamente assegurados.

No contexto atual, que há uma proposta legislativa de precarização da regulamentação de ingresso e permanência das pessoas com deficiência no mercado de trabalho, torna-se fundamental ampliar as discussões, não apenas em relação a importância do trabalho para a sobrevivência (econômica), mas, sobretudo, por ser o trabalho uma categoria central à vida humana; permitindo-nos ressignificar nossa 
essência e nos sentirmos sujeitos de nossas próprias histórias. Nesse sentido, Araújo (2020, p. 211) destaca a necessidade eminente de discutir a precarização da lei de $\operatorname{cotas}^{7}$ :

Se a legislação atual não tem sido suficiente para garantir a efetividade do processo inclusivo, uma notícia recente aumenta a preocupação. O projeto de lei (PL) $\mathrm{n}^{\circ}$ 1659/2019 enviado ao congresso nacional no dia 26 de novembro de 2019 propõe alterações na legislação no que diz respeito ao mercado de trabalho para as pessoas com deficiência; fazendo-se necessário, portanto, problematizar os principais aspectos do projeto de lei, ainda que esteja em tramitação.

O projeto de lei apresenta diretrizes para atualizar/reformular a lei de cotas e apresenta, entre outros pontos, uma flexibilização às empresas no que diz respeito à contratação de profissionais com deficiência. O projeto de lei 1659/2019 prevê, por exemplo, que a contração de um profissional que tenha uma deficiência considerada grave seja equivalente a contratação de dois profissionais com deficiência moderada/leve; prevê, ainda, que a não contratação de pessoa com deficiência possa ser "compensada" pelo pagamento de dois salários mínimos.

Percebe-se que as propostas do projeto de lei atendem mais “[...] a um projeto de flexibilização das regras atuais de contratação das pessoas com deficiência [...]” (ARAÚJO, 2020, p. 13) do que a uma preocupação efetiva com o ingresso e permanência das pessoas com deficiência no mercado de trabalho.

É justamente a importância do trabalho à vida humana que se busca discutir neste artigo. Ainda que a centralidade do trabalho se estenda a todas as pessoas, as marginalizações históricas sofridas pelas pessoas com deficiência, bem como o contexto de perspectiva de um retrocesso sem precedentes em relação às garantias legais a esse público, convocam-nos a ampliar as discussões sobre a importância social do trabalho. Para tanto, a compreensão da construção social do desenvolvimento, a partir de conceitos como a zona de desenvolvimento proximal e uma discussão teórica sobre a influência mediadora dos signos, em especial no aprendizado/desenvolvimento das crianças, subsidiam uma aproximação teórica entre o trabalho e o desenvolvimento humano.

\section{A Formação Social da Mente}

Pensar o desenvolvimento humano é uma tarefa complexa que envolve diversas áreas do conhecimento. Considerando as pesquisas vigentes em sua época, Vygotsky procurou confrontar os estudos de autores como Charlotte Buhler, Shapiro e Gerke, Guillaume e Meyerson com novas pesquisas envolvendo a psicologia do desenvolvimento humano. O autor foi pioneiro no desenvolvimento de

\footnotetext{
7 Lei 8.213/1991, que estabeleceu a política de cotas para inclusão de pessoas com deficiência e reabilitados no mercado de trabalho. A lei prevê que toda empresa com 100 ou mais empregados deve destinar de $2 \%$ a $5 \%$ dos postos de trabalho a pessoas com deficiência (BRASIL, 1991).
} 
pesquisas que demonstram que o desenvolvimento intelectual das crianças ocorre em função das interações sociais e das condições de vida.

Os estudos posteriores de Vygotsky foram baseados nas ideias de Marx, que considerava a existência de uma relação entre as mudanças na natureza humana a partir de mudanças históricas na sociedade e na vida material. Ainda que anteriormente outros autores tivessem considerado as proposições de Marx sobre o desenvolvimento da sociedade, Vygotsky foi o primeiro a tentar correlacioná-las a questões psicológicas concretas. Para o autor, “[...] a internalização dos sistemas de signos produzidos culturalmente provoca transformações comportamentais e estabelece um elo de ligação entre as formas iniciais e tardias do desenvolvimento individual” (VYGOTSKY, 1991, p. 11). Assim, para Vygotsky, na melhor tradição de Marx e Engels, as mudanças individuais ao longo do desenvolvimento têm sua origem na sociedade e na cultura.

As considerações iniciais supramencionadas reiteram a importância de haver, num ambiente educacional, um preparo geral dos profissionais que atuam na educação para que não desconsiderem as implicações das interações no ambiente escolar no desenvolvimento/aprendizado das crianças, pois, “[...] na medida em que o currículo fornece o material necessário, o desenvolvimento dos conceitos científicos precede o desenvolvimento dos conceitos espontâneos" (VYGOTSKY, 2001, p.105). Em relação às crianças com deficiência é preciso que exista um cuidado ainda maior, pois, assim como ressalta Gardou (2018), existe, historicamente, uma marginalização e privação da participação social efetiva desse público, seja na escola, na sociedade ou no trabalho. Se outrora o contexto geral era de marginalização, o que se quer para o presente é justamente uma sociedade inclusiva. A este respeito o autor destaca que:

A ideia de sociedade inclusiva repudia toda forma de manobra que aumente o número de pessoas impossibilitadas de se beneficiar dos meios de aprender, de se comunicar, de ter acesso a cultura, de trabalhar, de criar e de agir, em base de igualdade com os outros. Ela se opõe ao movimento que leva a dar mais aos já possuidores e partes reduzidas àqueles que, tendo menos, necessitam de um maior apoio. Ela questiona os mecanismos pelos quais os primeiros aumentam sua vantagem sobre os segundos, estabelecendo mais-valias e capitalizando os confortos (GARDOU, 2018, p. 24).

Para questionar um modelo de sociedade que privilegia o desenvolvimento de uns em detrimento de outros é preciso avaliar o processo de ensino e aprendizagem, sobretudo em relação ao desenvolvimento das crianças a partir da internalização dos signos. Depreende-se, pois, que a internalização dos signos culturalmente produzidos é importante para o desenvolvimento das crianças. Esses, por sua vez, não podem ser privilégio de crianças sem deficiência, ao contrário, pois se há alguma limitação física/motora/intelectual/social, há que se pensar em estratégias que possam minimizar/eliminar tais limitações e ampliar as potencialidades dessas crianças. 
"Signos e palavras constituem para as crianças, primeiro e acima de tudo, um meio de contato social com outras pessoas. As funções cognitivas e comunicativas da linguagem tornam-se, então, a base de uma forma nova e superior de atividade nas crianças, distinguindo-as dos animais" (VYGOTSKY, 1991, p. 23).

Admitir que a internalização dos signos significa uma mudança cognitiva nas crianças e que tal internalização reflete em um estágio novo e superior de atividade permite inferir que é justamente a relação social e seus reflexos na internalização das experiências vivenciadas que diferenciam as atividades humanas das atividades dos animais. É preciso que concebamos, ainda, que “[...] o sistema de atividade da criança é determinado em cada estágio específico, tanto pelo seu grau de desenvolvimento orgânico quanto pelo grau de domínio no uso de instrumentos (VYGOTSKY, 1991, p. 18).

Conforme destacado por Vygotsky, mais do que a idade biológica, é o grau de desenvolvimento orgânico em concomitância com o domínio do uso de instrumentos que potencializará o desenvolvimento e a mudança de estágio. "A experiência ensinou-nos que a criança com a zona mais extensa de desenvolvimento próximo terá melhor aproveitamento na escola. Esta medida dá-nos uma indicação acerca da dinâmica da evolução intelectual mais útil do que a idade mental” (VYGOTSKY, 2001, p. 103). Tão logo, evidencia-se que às crianças com deficiência pode ser necessário um investimento maior no contato com os signos e instrumentos, tendo em vista, sobretudo, que nem sempre estarão no mesmo grau de desenvolvimento que as crianças sem deficiência da mesma idade. Entretanto, a diferença entre idade/desenvolvimento não significa impossibilidade de aprendizagem, mas implica em entender, assim como nos diz Canguilhem ${ }^{8}$ (2009), que cada ser humano possui uma norma própria de vida, mais ou menos parecida com a dos demais, mas independentemente das diferenças e igualdades, à medida que interagimos com o meio ressignificamos nossas relações e construímos nossa própria forma de nos relacionarmos com o mundo.

Cabe-nos, portanto, enquanto sociedade, garantir o direito de interação social com os signos e instrumentos disponíveis, tanto quanto seja necessário para que individualmente as internalizações possam ser feitas. É preciso salientar que o processo de aprendizagem diz respeito não somente ao processo e a forma de ensino, mas, também, ao capital cultural já existente nos diversos sujeitos que participam do processo. Além disso, evidencia-se que "[...] o bom aprendizado" é somente aquele que se adianta ao desenvolvimento" (VYGOTSKY, 1991, p. 60). Ou seja, o aprendizado humano supõe uma construção social específica que ocorre anteriormente ao desenvolvimento. Depreende-se, pois, que a internalização é individual, necessita, logo, de tempos, instrumentos e signos específicos. Não há que se pensar, portanto, em um processo de desenvolvimento único para as crianças com ou sem deficiência.

\footnotetext{
${ }^{8}$ Médico e Filósofo Francês, reconhecido por questionar a lógica positivista da medicina, admitida, sobretudo no século XVIII. Para Canguilhem a vida não pode ser resumida a leis físico-químicas.
} 
A internalização dos signos é um processo que se dá em sociedade. O uso de signos é um caminho que se torna possível a partir do momento que se oportuniza à criança o contato com o objeto; tal processo se dá através de outras pessoas. "Essa estrutura humana complexa é o produto de um processo de desenvolvimento profundamente enraizado nas ligações entre história individual e história social" (VYGOTSKY, 1991, p. 24).

Embora a inteligência prática e o uso de signos possam operar independentemente em crianças pequenas, a unidade dialética desses sistemas no adulto humano constitui a verdadeira essência no comportamento humano complexo. Nossa análise atribui à atividade simbólica uma função organizadora específica que invade o processo do uso de instrumento e produz formas fundamentalmente novas de comportamento (VYGOTSKY, 1991, p. 20).

O uso dos signos, portanto, assim como demonstra Vygotsky, é um importante recurso no desenvolvimento humano; comportando-se e refletindo de forma diferente a cada etapa do desenvolvimento, além de representar, na vida adulta, uma função nova, internalizada e específica no uso dos instrumentos. Na vida adulta a internalização dos signos já está enraizada, entretanto, a continuidade do uso de instrumentos, como por exemplo, as ferramentas de trabalho, não pode e não deve ser desconsiderada; em especial às pessoas com deficiência que nem sempre tiveram a oportunidade - em etapas anteriores - de ter acesso, adequado às suas necessidades, aos diversos signos e instrumentos existentes na sociedade. Assim, o que se discute a seguir é justamente o trabalho do ponto de vista social, que nos humaniza e permite nossa ressignificação enquanto sujeitos sociais.

\section{A Ergologia e a Importância Social do Trabalho}

$\mathrm{Na}$ seção anterior discutimos as implicações da internalização dos signos nas diferentes etapas do desenvolvimento da criança. Mas, na vida adulta, o trabalho, entendido pela Ergologia como "um ato de natureza humana que engloba e restitui toda complexidade humana” (TRINQUET, 2010, p. 96), permitenos pensar na continuidade do desenvolvimento humano ao longo da vida, sobretudo a partir das relações de ressignificação do trabalho que, mesmo prescrito a priori, é sempre ressignificado em sua prática real. Para pensar o trabalho enquanto atividade humana é, pois, necessário entender a atividade como “[...] um impulso de vida, de saúde, sem limite predefinido, que sintetiza, cruza e liga tudo o que se representa separadamente (corpo/espírito; individual/coletivo; fazer/valores; privado/profissional; imposto/ desejado, etc.) " (DURRIVE; SCHWARTZ, 2007, p. 23).

A atividade de trabalho para a Ergologia é mais do que a execução de tarefas, trata-se de um constante debate de normas entre o que se espera que seja feito no trabalho, as experiências e internalizações de cada trabalhador, as diversas relações existentes no trabalho, entre tantos outros fatores 
que se correlacionam e tornam, sempre, a atividade de trabalho singular, intimamente relacionada ao corpo $\mathrm{si}^{9}$ dos trabalhadores.

Entender que o trabalho é uma constante dramática ${ }^{10}$, um constante jogo de valores entre as perspectivas de cada trabalhador, suas experiências e as renormatizações do trabalho prescrito; é o que possibilita ampliar a discussão para além da necessidade de sobrevivência, sendo, aliás, e a priori, um lugar de significação/ressignificação humana.

Relacionar o desenvolvimento das crianças a partir da internalização de signos com o desenvolvimento social a partir dos instrumentos no trabalho não é algo novo; Vygotsky admitiu uma analogia comparativa entre signos e instrumentos: "A invenção e o uso de signos como meios auxiliares para solucionar um dado problema psicológico (lembrar, comparar coisas, relatar, escolher, etc.) é análoga à invenção e uso de instrumentos, só que agora no campo psicológico” (VYGOTSKY, 1991, p. 38).

Para Albornoz (1994) não é exatamente o uso de instrumentos que torna o humano diferente do animal, mas sim, a liberdade que existe na relação homem/trabalho. A autora salienta que diferentemente dos animais os homens podem começar e parar uma tarefa, mudar o planejamento, recomeçar, enfim, é uma relação social complexa que envolve, para além da execução propriamente dita, o corpo si de cada trabalhador. Nesse sentido, Vygotsky (1991) salienta que tanto nos signos quanto nos instrumentos existe uma função mediadora, portanto, ainda que sejam diferentes, ambos podem ser incluídos na mesma categoria.

Para Schwartz (1996) o trabalho real, ou seja, aquele que realmente acontece, é sempre diferente do prescrito, sobretudo por cada trabalhador ser único e se relacionar de forma única com o trabalho. Tal entendimento da complexidade do trabalho se aproxima das proposições de Vygotsky, pois o autor destaca que o desenvolvimento social da mente se dá a partir da singularidade das experiências individuais em contato com as experiências coletivas. Para o autor, a vivência em sociedade nos permite um relacionamento com meio, no qual interferimos e somos interferidos por ele. Esse processo de construção social dialógica:

[...] é o que nós chamamos a zona de desenvolvimento proximal. Ela é a distância entre o nível de desenvolvimento real, que se costuma determinar através da solução independente de problemas, e o nível de desenvolvimento potencial, determinado através da solução de problemas sob a orientação de um adulto ou em colaboração com companheiros mais capazes (VYGOTSKY, 1991, p. 58).

\footnotetext{
9 Envolve a individualidade/subjetividade humana, mas é algo mais amplo que o sentido biológico; observando os sentimentos, valores, experiências e perspectivas futuras que nem sempre são expostas de forma consciente pelo trabalhador (SCHWARTZ; DURRIVE, 2007).

${ }^{10}$ No campo de trabalho sempre acontece algo, sobretudo através da reação dos trabalhadores mediantes as condições impostas. Essas reações devem ser compreendidas como dramas, mais precisamente: dramáticas do uso de si (SCHWARTZ; DURRIVE, 2007).
} 
Destaca-se que para Vygotsky a zona de desenvolvimento proximal se interessa não pelo desenvolvimento biológico, e sim, pelo desenvolvimento real em contato proximal com "companheiros mais capazes". Tal desenvolvimento, que é proximal, sobretudo pelo contato social, não se estabelece apenas pelo fato de estar junto, mas está intimamente ligado às experiências anteriores, as perspectivas do presente e também aos instrumentos e signos disponíveis. Além disso, a internalização, que se dá posteriormente, é sempre refletida em novas experiências que, por consequente, formam-se e reformamse constantemente em um contínuo constructo de internalizações a partir de zonas proximais/sociais de desenvolvimento.

Entender tal relação é fundamental para alcançar o que Gardou (2018) compreende por sociedade inclusiva, pois admitir que independentemente das limitações as pessoas com deficiência se desenvolvem a partir do nível de desenvolvimento real que se encontram em uma relação dialógica com uma zona de desenvolvimento proximal, possibilita-nos afastar um conceito de deficiência baseado na perspectiva de "falta de" e aproximar de uma abordagem que, à luz dos preceitos de Diniz (2007), não desconsidera as limitações do corpo com lesão, mas compreende a integralidade humana e destaca as potencialidades de cada pessoa, sobretudo a partir da oportunidade de participação efetiva na sociedade, seja na escola, no lazer ou no trabalho.

Ampliando a compreensão do trabalho real, e, por conseguinte, sua importante função social, as proposições de Schwartz (1996) nos ajudam, sobretudo por destacar que nenhum trabalho é igual a outro, assim como nenhum trabalhador é igual a outro. Não há que se esperar, portanto, que os instrumentos usados por um trabalhador sem deficiência sejam os mesmos usados por um trabalhador com deficiência. Reitera-se, logo, a centralidade da tecnologia assistiva ${ }^{11}$ na construção de instrumentos que permitam uma participação efetiva de profissionais com deficiência no mundo trabalho.

Garantir instrumentos de trabalho adequados às necessidades dos profissionais com deficiência não significa esperar que o resultado do trabalho seja igual para todos os trabalhadores. Afinal, para a Ergologia, o trabalho real, ou seja, aquele que ocorre de fato, é, mesmo que minimamente, diferente do prescrito/normativo, pois há sempre um renormalização do trabalhador. Essa diferença se dá pela individualidade humana: cada trabalhador é carregado de história, de vivências, de experiências e de perspectivas; tais características estão intimamente ligadas ao corpo de cada trabalhador e não podem ser desconsideradas nas relações de trabalho.

Nas diversas relações sociais, e, portanto, no trabalho, as individualidades humanas se coadunam, sendo, logo, uma construção individual, pois envolve o corpo de cada trabalhador, mas também uma construção coletiva, pois há, sempre, uma troca dialógica, na qual é possível aprender e ensinar ao mesmo

\footnotetext{
11 Todo e qualquer recurso (seja de alto ou baixo custo) que auxilie a pessoa com deficiência na execução de alguma tarefa. No mercado de trabalho a tecnologia assistiva pode ser compreendida como um aprimoramento do meio ambiente de trabalho, tornando-o acessível também às pessoas com deficiência (ARAÚJO, 2020).
} 
tempo. Desse modo, pensar o trabalho a partir dessa oportunidade de ressignificação constante permite afirmar que o trabalho é, mais do que um meio de sobrevivência, uma forma de humanização, ressignificação e construção social; tão logo, é preciso que concebamos que o trabalho é um direito humano, e, portanto, às pessoas com deficiência esse direito não pode ser privado. Deve, inclusive, ser pensado para além da inclusão, também como um novo espaço de desenvolvimento proximal, no qual as limitações corpóreas possam ser ressignificadas e as potencialidades compartilhadas.

O conceito ergológico de Entidades Coletivas Relativamente pertinentes (ECRP) discutido por Efros (2014) nos ajuda a demonstrar a importância da construção coletiva do trabalho. As discussões entorno do conceito de ECRP ressaltam que "atos exercidos sozinhos podem ser também indiretamente endereçados aos membros ausentes de um coletivo" (EFROS, 2014, p. 420). As entidades são coletivas, pois ainda que implicitamente, as "ações individuais" sempre coadunarão em ações coletivas, ou ao contrário, ainda que diferentemente em cada sujeito, pois cada trabalhador, diante de seu corpo si, terá uma ressignificação perante às relações de trabalho.

As entidades são relativamente pertinentes, pois um coletivo não pode ser forjado, previsto ou antecipado. As relações são construídas no trabalho real, mais uma vez fica evidenciado as individualidades humanas, pois as afinidades, os interesses, a necessidade de produtividade, entre tantos outros fatores, subsidiam a construção de uma ECRP, e “[...] as entidades coletivas são "pertinentes", uma vez que, sem a instauração dessas relações, "isso não poderia funcionar"; a existência delas é essencialmente ligada às questões de eficácia, as quais é preciso analisar em cada caso” (EFROS, 2014, p. 420).

Percebe-se que as relações de trabalho são sempre uma construção/reconstrução social; são individuais, mas também coletivas; permitem ao trabalhador aprender, mas também ensinar; expõem ao trabalhador objetivos a serem alcançados, mas, esses objetivos são cumpridos diferentemente por cada trabalhador, ainda que o objetivo final seja igualmente alcançado por todos. Há que se pensar no trabalho como uma oportunidade de aprender, de ensinar, de compartilhar, enfim, de viver.

A proposta de relacionar o desenvolvimento humano com as relações sociais no trabalho é um tema de alcance amplo e merece ser aprofundado em diversas dimensões sociais, entretanto, o objetivo da reflexão aqui proposta é ampliar o olhar para as pessoas com deficiência, que, conforme destaca Araújo (2020), ainda são excluídas ou colocadas em subvagas $^{12}$ no mercado de trabalho. Logo, se o objetivo é a construção de uma sociedade inclusiva, não há outro caminho senão o da ressignificação ética das atitudes individuais e coletivas (VOLTOLINI, 2019). Nesse contexto, o trabalho, perante sua centralidade nas relações sociais, não pode ter sua importância subjugada. Trabalhar é mais do que executar uma tarefa. É

\footnotetext{
12 Entende-se por subvagas o oferecimento de vagas às pessoas com deficiência aquém de sua qualificação/formação. Isso ocorre quando as Instituições se preocupam apenas em cumprir a legislação de reservas de vagas, mas não se preocupam com suas funções sociais. (ARAÚJO, 2020).
} 
uma transformação de objetos - físicos ou não - mas também uma transformação interna e social. É, logo, um constructo humanizador, portanto, não pode ser privilégio de alguns.

\section{Considerações Finais}

Longe de querer igualar os conceitos de signo e instrumento, objetivou-se demonstrar que ambos têm função mediadora nas relações sociais que circundam a existência humana. Tão logo, admitir que os signos são internalizados nas diferentes etapas do desenvolvimento das crianças não impede de admitir que o uso de instrumentos bem como as relações sociais no trabalho, continuam a possibilitar o desenvolvimento humano - ressignificando-nos e ressignificando constantemente nossa história social, em parte individual, em parte coletiva.

As proposições da Ergologia sobre o trabalho real permitem dialogar com as discussões de Vygotsky acerca do uso de signos e instrumentos no desenvolvimento Humano. Reconhecer que a aprendizagem precede a internalização de conceitos e que a internalização é um processo individual, coletivo e mediado, permite-nos pensar na centralidade do trabalho enquanto categoria social. Há que se pensar, portanto, num trabalho como ambiente de aprendizado, de ensinamento e de construção mediada pelo uso de instrumentos e pelas relações sociais.

Reconhecer a importância social do trabalho é fundamental para alcançarmos uma sociedade inclusiva; pois, se queremos incluir em todas as instancias sociais, não há espaço para privar as pessoas com deficiência do mundo do trabalho. Sendo o trabalho um ambiente de ressignificação individual e coletiva, este não pode ser privilégio de alguns em detrimento de outros. E mais, ao sabermos que o desenvolvimento humano ocorre a partir do uso de signos e instrumentos em uma zona de desenvolvimento proximal, cabe-nos, enquanto sociedade, garantir que as condições sociais se instaurem tanto quanto seja necessário para que cada indivíduo possa se desenvolver. O que é válido para todas as instancias sociais, e por óbvio, também para o trabalho. Depreende-se, pois, que o trabalho é um espaço de desenvolvimento/formação/compartilhamento e humanização para as pessoas com deficiência assim como para as pessoas sem deficiência, mas, mais do que isso, é um direito de todos, local onde nos ressignificamos enquanto sujeitos e enquanto sociedade, construindo constantemente uma nova história - individual e coletiva. 


\section{REFERENCIAS}

ALBORNOZ, Suzana. O que é Trabalho. 6a ed. São Paulo: Brasiliense, 1994.

ARAÚJO, Naim Rodrigues de. O Trabalho De Professoras Com Deficiência Visual: Uma análise político-social da inclusão profissional na rede regular de ensino de Belo Horizonte. Dissertação de Mestrado. Belo Horizonte MG, Faculdade de Educação da Universidade Federal de Minas Gerais, 2020, $233 f$.

BRASIL, Constituição da República Federativa do Brasil de 1988. Disponível em: http://www.planalto.gov.br/ccivil 03/constituicao/constituicao.htm. Acesso em: 20 set. 2020.

BRASIL, Lei $\mathrm{n}^{\mathrm{o}}$ 8.112, de 11 de dezembro de 1990. Disponível em: http://www.planalto.gov.br/ccivil 03/leis/L8112cons.htm. Acesso em: 21 jun. 2017.

BRASIL, Lei $\mathrm{n}^{\circ} 8.213$ de 24 de julho de 1991. Disponível em: http://www.planalto.gov.br/ccivil 03/leis/L8213cons.htm. Acesso em: 21 jun. 2019.

BRASIL, Resolução no 630 de 27 de outubro de 1998. Disponível em: https://pt.slideshare.net/asustecnologia/resoluo-630-98. Acesso em 21 jun. 2017.

BRASIL. Lei no 9.394 de 20 de dezembro de 1996. Estabelece as diretrizes e bases da educação nacional. Disponível em: http://www.planalto.gov.br/ccivil 03/Leis/L9394.htm. Acesso em: 2 fev. 2018.

BRASIL, Lei $\mathrm{n}^{\mathrm{o}}$ 13.146, de 6 de julho de 2015. Disponível em: http://www.planalto.gov.br/ccivil 03/Ato2015-2018/2015/Lei/L13146.htm. Acesso em: 06 set. 2016.

BRASIL, Projeto de lei 6.159 de 26 de novembro de 2019. Disponível em: https://www.camara.leg.br/. Acesso em: 04 dez. 2019.

CANGUILHEM, Georges. O Normal e o Patológico. Tradução de Maria Thereza Redig De Carvalho Barrocas. $6^{a}$ ed. Rio de Janeiro: Forense Universitária, 2009.

DINIZ, Débora. O que é deficiência. $1^{\circ}$ ed. São Paulo: Brasiliense, 2007.

DINIZ, Débora; BARBOSA, Lívia. Direitos Humanos e as pessoas com deficiência no Brasil. In: VENTURI, Gustavo (ORG.). Direitos Humanos: Percepções Da Opinião Pública. Brasília: Secretaria de Direitos Humanos, 2010. P. 201-217.

GARDOU, Charles. A sociedade Inclusiva: falemos dela! Não há vida minúscula. Coordenação de Mônica Maria Farid. Tradução de Cleonice Paes Mourão e Marcia Bandeira. $1^{\circ}$ ed. Belo Horizonte MG, Fino traço: Editora UFMG, 2018.

HOLZ, Edvalter Becker; BIANCO, Mônica de Fátima. O conceito de trabalho na Ergologia: da representação à atividade. Trabalho \& Educação, v.23, n.2 p.157-173, Belo Horizonte, mai. /ago. 2014.

MENEGHETTI, Francis Kanashiro. O que é um Ensaio-Teórico?. RAC, Curitiba, v. 15, n. 2, p. 320332, mar. /abr. 2011. Disponível em: https://www.scielo.br/j/rac/a/4mNCY5D6rmRDPWXtrQQMyGN/?lang=pt. Acesso em: 01 jun. 2021. 
MINAYO, Maria Cecília de Souza. et al. Pesquisa Social: Teoria, Método e Criatividade. 21ª ed. Petrópolis: Vozes, 2002.

SCHWARTZ, Yves. Trabalho e valor. Tempo Social, Rev. Sociol. USP, S. Paulo, v. 8, n. 2, p.147-158, out. 1996.

SCHWARTZ. Yves. Entrevista. In Trabalho, Educação e Saúde. RJ: Fiocruz, v.4, n 2, p. 457 - 466, 2006.

SCHWARTZ, Yves; DURRIVE, Louis. Trabalho \& Ergologia: conversas sobre a atividade humana. 1. ed. Rio de Janeiro: Editora EDUFF, 2007.

TRINQUET, Pierre. Trabalho e Educação: o método ergológico. Revista HISTEDBR, Campinas, v. 10, n. número especial, p. 93-113, ago. 2010.

VOLTOLINI, Rinaldo. Interpelações Éticas à Educação Inclusiva. Educação \& Realidade, Porto Alegre, v.44, n.1, 2019. Disponível em: http://dx.doi.org/10.1590/2175-623684847. Acesso em: 19 mai. 2019.

VYGOTSKY, Lev Semionovitch. A formação social da mente: o desenvolvimento dos processos psicológicos superiores. 4. ed. São Paulo: Martins Fontes, 1991.

VYGOTSKY, Lev Semionovitch. Pensamento e Linguagem. Edição eletrônica: Ed Ridendo Castigat Mores, 2001. 